\title{
Surgical risk of preoperative malperfusion in acute type A aortic dissection
}

\author{
Evaldas Girdauskas, MD, Thomas Kuntze, MD, Michael A. Borger, MD, PhD, Volkmar Falk, MD, PhD, and \\ Friedrich-Wilhelm Mohr, MD, PhD
}

\begin{abstract}
Objective: Patients who have type A dissection with preoperative malperfusion syndromes are believed to be at extremely high surgical risk. Our aim was to evaluate perioperative and long-term results of patients with preoperative malperfusion.
\end{abstract}

\begin{abstract}
Methods: A total of 276 patients (174 men; mean age $59.5 \pm 13.4$ years) underwent surgery for acute type A dissection between October 1994 and January 2008. Preoperative malperfusion syndromes were diagnosed in $93(33.7 \%)$ patients (group I) and involved coronary circulation in $41(15 \%)$ patients, central nervous system in $39(14 \%)$ patients, limb ischemia in $32(11.6 \%)$ patients, and mesenteric circulation in $8(3 \%)$ patients. Postoperative results were compared between patients with preoperative malperfusion and those without this complication (group II, $\mathrm{n}=183$ ).
\end{abstract}

Results: In-hospital mortality was $29.0 \%$ in group I versus $13.6 \%$ in group II $(P=.002)$. The postoperative intensive care unit stay was longer $(11.4 \pm 9.7$ vs $7.7 \pm 6.9$ days; $P=.04)$ in the malperfusion group. A total of 6 $(75 \%)$ patients with mesenteric malperfusion died. Long-term follow-up (range, 1-122 months postoperatively) was available in $100 \%$ of survivors. One-year and 5-year overall survivals were $49.8 \% \pm 11.8 \%$ and $41.8 \% \pm$ $12.6 \%$ in group I versus $70.4 \% \pm 7.6 \%$ and $56 \% \pm 10.4 \%$ in group II $(P=.005)$. Cox regression analysis identified preoperative malperfusion as a significant risk factor for long-term mortality after surgery for type A dissection (hazard ratio, $1.7 ; 95 \%$ confidence intervals, $1.2-3.1$ ).

Conclusions: Preoperative malperfusion is a significant risk factor influencing perioperative and long-term survival after surgery for acute type A dissection. Percutaneous interventional procedures and delayed surgery should be considered in patients with clinically apparent mesenteric malperfusion because of the dismal prognosis of immediate surgical therapy. (J Thorac Cardiovasc Surg 2009;138:1363-9)

Despite numerous innovations in contemporary perioperative anesthetic and surgical management, early mortality after surgical treatment of acute type A aortic dissection remains high, ranging from $15 \%$ to $30 \%$ in published series. ${ }^{1-3}$ Although numerous risk factor constellations have been evaluated, the majority of published studies identified preoperative status of the patient as the most important predictor of in-hospital outcome. ${ }^{3-6}$ Approximately one third of all patients with acute type A dissection have preoperative end-organ malperfusion syndromes. ${ }^{2,7}$ These patients are believed to be at extremely high risk for poor in-hospital outcome, ${ }^{2,7,8}$ but relatively little is known of their long-term prognosis.

The aim of this study was to evaluate perioperative and long-term results of patients with preoperative malperfusion in a relatively large single-center retrospective study.

\footnotetext{
From the Department of Cardiac Surgery, Heart Center Leipzig, Leipzig, Germany. Received for publication Oct 25, 2008; revisions received Feb 20, 2009; accepted for publication April 12, 2009; available ahead of print Sept 7, 2009.

Address for reprints: Evaldas Girdauskas, MD, Department of Cardiac Surgery, Herzzentrum Leipzig, Strümpellstr. 39; 04289 Germany (E-mail: evagird@centras.lt). $0022-5223 / \$ 36.00$

Copyright (C) 2009 by The American Association for Thoracic Surgery doi:10.1016/j.jtcvs.2009.04.059
}

\section{METHODS}

We reviewed our institutional aortic surgery database to identify patients who underwent surgery for acute type A dissection between October 1994 and January 2008. A total of 276 consecutive patients underwent surgery on an emergency basis for acute type A aortic dissection during this period. $\mathrm{Pa}-$ tients who had preoperative malperfusion syndromes $(n=93)$ were identified and compared with those without end-organ malperfusion $(n=183)$. Approval of the ethics committee of the University Leipzig (Reg. No. 199-2005) was obtained in October 2005. The individual consent for the study was waived.

\section{Surgical Management}

Standardized surgical and anesthetic protocols were used with only minor changes over time. In brief, cardiopulmonary bypass (CPB) was instituted with right axillary or femoral arterial perfusion and right atrial venous drainage. Femoral artery cannulation was used more frequently early in this series, whereas axillary artery cannulation has been our technique of choice for the past 8 years. We currently use femoral artery cannulation only when the right axillary artery is found to be dissected on preoperative computed tomography. Systemic cooling was carried out down to an esophageal temperature of $20^{\circ} \mathrm{C}$ with a maximal $\mathrm{CPB}$ temperature gradient of $6{ }^{\circ} \mathrm{C}$. In more recent years, antegrade selective cerebral perfusion $\left(10 \mathrm{~mL} \cdot \mathrm{kg}^{-1} \cdot \mathrm{min}^{-1}\right)$ was applied during circulatory arrest at a core temperature of $23{ }^{\circ} \mathrm{C}$ to $25^{\circ} \mathrm{C}$.

The aortic root procedure was performed during the cooling phase. The primary aim was to save the native aortic valve when it appeared morphologically normal. Directly before systemic perfusion was stopped, ice packs were placed around the head and $100 \mathrm{mg}$ dexamethasone was administered intravenously. Distal aortic repair was always performed with an open technique. Proximal hemiarch replacement was our procedure of choice for patients with acute type A aortic dissection. Total arch replacement was reserved for patients with aortic arch entry tears involving the supra-aortic orifices, as well 


\section{Abbreviations and Acronyms \\ $\mathrm{CPB}=$ cardiopulmonary bypass \\ $\mathrm{TIA}=$ transient ischemic attack}

as for patients with an enlarged aortic arch or other indications as described by Crawford, Kirklin, and Naftel. ${ }^{9}$ Antegrade graft perfusion was implemented during reperfusion when the femoral artery was cannulated. The temperature gradient was kept below $6^{\circ} \mathrm{C}$ during rewarming.

\section{Definition of Malperfusion}

Malperfusion syndromes were diagnosed if patients with acute type A aortic dissection had symptoms and signs attributable to disturbed blood flow to defined end-organ systems. Radiographic or surgical evidence of dissection involving appropriate aortic branch vessels was required for confirmation of malperfusion syndrome. Evidence of a dissection membrane in aortic branch vessels without corresponding clinical signs or symptoms was not classified as malperfusion. In those patients who were intubated or receiving cardiopulmonary resuscitation when they were brought to our hospital, we attempted to determine whether symptoms of malperfusion occurred (particularly focal neurologic symptoms and/or abdominal pain or tenderness) after the onset of chest pain, as noted by the emergency physician or referring hospital. Supportive information from family members was available in some cases.

Malperfusion syndromes were subclassified as coronary (ischemic electrocardiographic changes, elevation of creatinine kinase MB or troponin levels, and regional wall motion abnormalities on echocardiography), central nervous system (transient ischemic attack [TIA], stroke, paraplegia/paraparesis), limb (loss of pulses, clinical signs of limb ischemia, and elevated creatinine kinase level), or mesenteric malperfusion (abdominal tenderness, bowel paralysis, lactate acidosis). Renal malperfusion was not analyzed separately because of the difficulty making this diagnosis preoperatively (ie, renal insufficiency can be caused by a variety of preoperative factors with or without compromise of the renal arterial branch).

\section{Follow-up}

Follow-up was performed in $100 \%$ of hospital survivors. Follow-up consisted of a telephone interview with the patients or patients' family members, as well as a written questionnaire sent to the patients' general practitioners. All imaging data obtained during the postoperative course (echocardiography reports and computed tomography/magnetic resonance imaging) were forwarded to our center for documentation purposes. In addition, $98(43.6 \%)$ patients were directly examined in our outpatient clinic.

\section{Statistical analysis}

Standard definitions were used for patient variables and outcomes. Categorical variables are expressed as percentages and continuous variables are expressed as mean $\pm \mathrm{SD}$ throughout the article. All statistical analyses were performed with the SPSS 14.0 software (SPSS, Inc, Chicago, Ill). Twotailed Student $t$ test for continuous variables and $\chi^{2}$ test for categorical variables were used to make univariate comparisons between groups. Survival analysis was performed according to the methods of Kaplan and Meier, and statistical differences were analyzed by the log-rank test. A multivariable analysis (ie, Cox regression) of risk factors for mortality was performed. All variables were screened in the univariate model and considered for clinical relevance before they were included in the multivariate model.

\section{RESULTS}

Malperfusion syndromes were diagnosed in 93 (33.7\%) of 276 patients with acute type A dissection (group I) and in- volved coronary circulation in $41(15 \%)$ patients, central nervous system in $39(14 \%)$ patients, limb ischemia in 32 $(11.6 \%)$ patients, and mesenteric circulation in $8(3 \%)$ patients. Single end-organ malperfusion syndrome was present in $75(81 \%)$ group I patients, two different malperfusion syndromes occurred in $12(13 \%)$ patients, three in $5(5 \%)$ patients, and four in $1(1 \%)$ patient. With the exception of the presence of hemodynamic instability, demographics and preoperative variables were comparable between patients with preoperative malperfusion and without it (group II, see Table 1).

Intraoperative management of both groups is displayed in Table 2. There were no major differences between groups with regard to CPB management or proximal/distal extent of the surgical procedure. There was a tendency, however, toward longer CPB and aortic crossclamp times in the malperfusion group.

Comparisons of postoperative outcomes between groups are presented in Table 3. In-hospital mortality was $29.0 \%$ in group I versus $13.6 \%$ in group II $(P=.002)$. Patients in the malperfusion group had a substantially more complicated postoperative course than did patients without malperfusion, resulting in significantly longer intensive care unit stays ( $11.4 \pm 9.7$ vs $7.7 \pm 6.9$ days; $P=.04)$. Secondary interventions to treat postoperative persistent or newly occurring malperfusion were performed in 4 patients, 3 of which were required in patients without preoperative malperfusion. Two of these patients underwent open surgical proceduresextra-anatomic axillo-right femoral artery bypass for intermittent ischemia of the lower extremities in 1 patient and open fenestration of the abdominal aorta for visceral ischemia in the other. The remaining 2 patients underwent percutaneous endovascular procedures - stenting of the brachiocephalic trunk because of dissection-induced filiform stenosis and corresponding right hemispheric TIA in 1 patient and endovascular fenestration of the left external iliac artery and stenting of the left renal artery for clinically evident hypoperfusion in the other.

Follow-up information was available for all discharged patients and was of comparable duration between groups. After a mean follow-up period of $33.3 \pm 31.8$ months (range, $0.1-122$ months), 39 (42\%) patients were alive in group I versus $118(64 \%)$ patients in group II $(P=.001)$. The overall survival after 5 years' follow-up was $41.8 \% \pm 12.6 \%$ in group I versus $56.0 \% \pm 10.4 \%$ in group II $(P=.001$ by $\log$-rank test, Figure 1). No malperfusion-related interventions were required during follow-up in either group.

A total of 8 variables reached statistical significance in the univariate model and were included in the Cox regression analysis of risk factors for long-term mortality. Preoperative malperfusion (hazard ratio, 1.7; 95\% confidence intervals, 1.2-3.1) and preoperative shock were the only independent risk factors for long-term mortality (Table 4). The date of operation had no significant impact on perioperative or longterm mortality. 
TABLE 1. Preoperative variables

\begin{tabular}{lccc}
\hline \multicolumn{1}{c}{ Variable } & $\begin{array}{c}\text { MPS } \\
(\mathbf{n = 9 3 )}\end{array}$ & $\begin{array}{c}\text { No MPS } \\
(\mathbf{n = 1 8 3})\end{array}$ & $\boldsymbol{P}$ value \\
\hline Mean age (y) & $59.9 \pm 11.3$ & $60.1 \pm 14.1$ & .9 \\
Male & $62(67)$ & $112(61)$ & .4 \\
Arterial hypertension & $77(83)$ & $149(81)$ & .8 \\
Bicuspid aortic valve & $3(3)$ & $12(7)$ & .2 \\
Coronary artery disease & $15(16)$ & $26(14)$ & .6 \\
Preoperative shock* & $27(29)$ & $26(14)$ & .01 \\
Pericardial tamponade & $17(18)$ & $21(12)$ & .1 \\
Previous cardiac surgery & $11(12)$ & $17(9)$ & .5 \\
Marfan syndrome & $9(10)$ & $14(8)$ & .6 \\
Aortic insufficiency & $46(49)$ & $89(49)$ & .9 \\
$\quad$ (moderate or severe) & & & \\
Median time to surgery $(\mathrm{h})$ & 11 & 11.5 & .7 \\
\hline
\end{tabular}

Data are presented as numbers $(\%)$ or as mean \pm SD. MPS, Malperfusion syndrome. *Defined as severe hemodynamic instability associated with hypotension requiring high-dose inotropic/vasopressor support $\left(>10 \mu \mathrm{g} \cdot \mathrm{kg}^{-1} \cdot \mathrm{min}^{-1}\right)$, metabolic acidosis, peripheral vasoconstriction, and oliguria.

\section{Effects of End-Organ-Specific Malperfusion on Mortality}

More than one malperfusion syndrome was present in 18 patients, and the multiple syndromes were associated with significantly higher in-hospital mortality than were single malperfusion syndromes ( $44.4 \%$ vs $25.3 \% ; P=.002)$.

Coronary malperfusion was diagnosed in 41 patients, of whom $23(56 \%)$ underwent antiplatelet therapy for acute coronary syndrome (aspirin and clopidogrel) in the referring hospital before the diagnosis of acute type A dissection was established. In addition, systemic thrombolysis was performed in $5(12 \%)$ patients. A total of $20(49 \%)$ patients with coronary malperfusion required inotropic support preoperatively, and surgery was started during cardiopulmonary resuscitation in $8(20 \%)$ patients. Surgical strategy included reconstruction and reimplantation of coronary buttons in $23(56 \%)$ patients (complete root replacement in 15 and valve-sparing procedure in 8 ) and coronary artery bypass graft procedures in $21(51 \%)$ patients. Coronary ostial reimplantation was performed to treat ostium-type coronary

TABLE 2. Intraoperative management

\begin{tabular}{lccc}
\hline \multicolumn{1}{c}{ Variable } & $\begin{array}{c}\text { MPS } \\
(\mathbf{n = 9 3 )}\end{array}$ & $\begin{array}{c}\text { No MPS } \\
(\mathbf{n = 1 8 3 )}\end{array}$ & $\boldsymbol{P}$ value \\
\hline Axillary artery perfusion & $51(55)$ & $98(54)$ & .9 \\
CPB time (min) & $206.7 \pm 94.8$ & $183 \pm 67.8$ & .054 \\
Crossclamp time (min) & $100.8 \pm 50.4$ & $90.0 \pm 42.9$ & .1 \\
Circulatory arrest time (min) & $28.4 \pm 16.1$ & $25.6 \pm 14.8$ & .2 \\
Lowest core temperature $\left({ }^{\circ} \mathrm{C}\right)$ & $22.0 \pm 4.0$ & $22.7 \pm 4.1$ & .3 \\
Antegrade cerebral perfusion & $26(28)$ & $53(29)$ & .9 \\
Aortic root replacement & $35(38)$ & $58(32)$ & .4 \\
Aortic root reconstruction & $32(34)$ & $59(32)$ & .7 \\
Hemiarch replacement & $34(37)$ & $79(43)$ & .3 \\
Total arch replacement & $31(33)$ & $48(26)$ & .3 \\
\hline
\end{tabular}

Data are presented as numbers (\%) or as mean $\pm \mathrm{SD} . M P S$, Malperfusion syndrome; $C P B$, cardiopulmonary bypass.
TABLE 3. Postoperative outcomes

\begin{tabular}{lccc}
\hline \multicolumn{1}{c}{ Variable } & $\begin{array}{c}\text { MPS } \\
(\mathbf{n = 9 3 )}\end{array}$ & $\begin{array}{c}\text { No MPS } \\
(\mathbf{n = 1 8 3 )}\end{array}$ & $\boldsymbol{P}$ value \\
\hline ICU stay (d) & $11.4 \pm 9.7$ & $7.7 \pm 6.9$ & .04 \\
Respiratory dysfunction & $19(20)$ & $19(10)$ & .03 \\
Tracheostomy & $16(17)$ & $18(10)$ & .1 \\
Renal failure (hemodialysis) & $40(43)$ & $40(22)$ & .001 \\
Low cardiac output syndrome & $21(23)$ & $27(15)$ & .2 \\
Stroke & $20(22)$ & $17(9)$ & .02 \\
Reoperation for bleeding & $21(23)$ & $29(17)$ & .2 \\
Hospital mortality & $27(29)$ & $25(14)$ & .002 \\
\hline
\end{tabular}

Data are presented as numbers (\%) or as mean \pm SD. MPS, Malperfusion syndrome; $I C U$, intensive care unit.

malperfusion (ie, dissection involving coronary ostia without extension into the coronary artery itself). The right coronary artery was involved more frequently than the left coronary system $(53 \%$ vs $27 \%)$, and both coronary arteries were affected in $20 \%$ of patients. Isolated saphenous vein bypass graft to the right coronary artery was performed in 13 patients, and bypass grafting of both the left and right coronary artery systems was performed in 5 patients. The remaining 3 patients underwent isolated bypass grafting of the left coronary system (ie, left anterior descending and circumflex arteries). A total of $5(24 \%)$ patients underwent a rescue coronary bypass graft procedure after a futile attempt to wean from CPB, 3 of whom had previous coronary ostial reimplantation.

High-dose inotropic support $\left(>10 \mu \mathrm{g} \cdot \mathrm{kg}^{-1} \cdot \mathrm{min}^{-1}\right)$ was required for weaning from $\mathrm{CPB}$ in $15(37 \%)$ patients with coronary malperfusion. An intra-aortic balloon pump was used in $2(5 \%)$ patients without residual dissection in the descending aorta, and extracorporeal membrane oxygenation was used in $8(18 \%)$ patients with severe refractory low

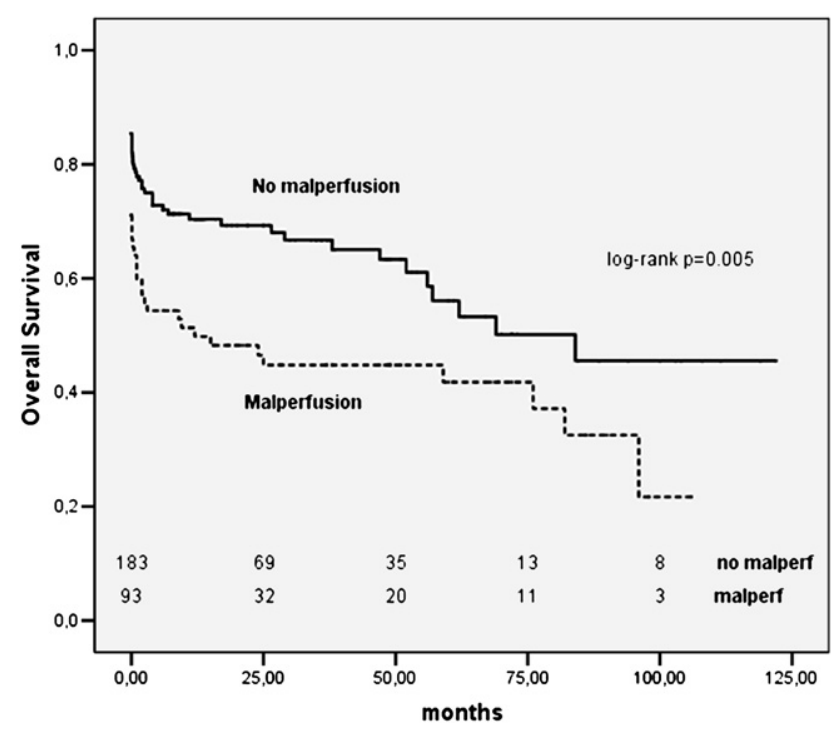

FIGURE 1. Overall survival (Kaplan-Meier). 
TABLE 4. Risk factors influencing overall survival (Cox regression analysis)

\begin{tabular}{lccc}
\hline \multicolumn{1}{c}{ Variable } & Hazard ratio & $\mathbf{9 5} \% \mathbf{C I}$ & $\boldsymbol{P}$ value \\
\hline $\begin{array}{c}\text { Preoperative } \\
\text { malperfusion }\end{array}$ & 1.7 & $1.2-3.1$ & .03 \\
$\begin{array}{l}\text { Preoperative shock } \\
\text { CI, Con }\end{array}$ & 2.5 & $1.3-5.6$ & .04 \\
\hline
\end{tabular}

$C I$, Confidence intervals.

cardiac output syndrome. In-hospital mortality was significantly higher in patients with coronary malperfusion than in patients without it $(39.4 \%$ vs $17.1 \% ; P=.004)$. A total of 4 such patients died intraoperatively because of inability to wean from CPB. Five-year overall survival was $21.9 \% \pm$ $10.7 \%$ for patients with coronary malperfusion.

A total of 29 patients had cerebral malperfusion (Table 5). There were no major differences in the preoperative characteristics and operative strategy between patients with cerebral malperfusion and those without it. A total of 21 $(72 \%)$ patients with cerebral malperfusion underwent axillary artery cannulation versus $8(28 \%)$ patients who were cannulated in the femoral artery. There was a tendency toward more extensive cooling on CPB $\left(20.9^{\circ} \mathrm{C} \pm 2.8^{\circ} \mathrm{C}\right.$ vs $\left.22.7^{\circ} \mathrm{C} \pm 4.1^{\circ} \mathrm{C} ; P=.08\right)$ and more frequent replacement of the total arch $(43 \%$ vs $27 \% ; P=.1)$ in the cerebral malperfusion group. In-hospital mortality was not significantly different between patients with cerebral malperfusion and without it $(20.7 \%$ vs $20.8 \% ; P=.9)$. There were two cerebral deaths because of massive postoperative cerebral edema in the cerebral malperfusion group. Four $(25 \%)$ of the 16 patients with preoperative stroke died.

Neurologic outcome was analyzed depending on the type of preoperative cerebral dysfunction (Table 5). A total of 15 $(52 \%)$ patients with cerebral malperfusion recovered without any neurologic sequelae postoperatively. Neurologic outcome was unfavorable (as compared with preoperative neurologic status) in $5(17 \%)$ patients ( 2 patients with preoperative stroke, 2 patients with TIA, and 1 patient with encephalopathy). Five-year survival was not significantly different between patients with cerebral malperfusion and without it $(53.8 \% \pm 14.6 \%$ vs $51.8 \pm 8.6 \%$; log-rank $P=.9$ ). Overall survival was not influenced by the presence of preoperative stroke $(\log -\operatorname{rank} P=.9)$.

Preoperative spinal malperfusion was diagnosed in $10 \mathrm{pa}-$ tients and was transient in 4 (Table 5). Immediate surgical repair of the proximal aorta resulted in an uneventful recovery without residual paraplegia in $6(60 \%)$ patients. One patient died of low cardiac output on the second postoperative day (in-hospital mortality of $10 \%$ ) and neurologic outcome could not be assessed. Two further patients died during follow-up (owing to oral anticoagulant-associated intracerebral hemorrhage 76 months postoperatively and owing to sepsisinduced multiorgan failure 2 months postoperatively). Only 1 patient (of 7 survivors) has residual left-dominant paraplegia associated with chronic neuropathic pain syndrome.
TABLE 5. Characteristics of central nervous system malperfusion

\begin{tabular}{lclc}
\hline \multicolumn{1}{c}{ Pathology } & No. $=\mathbf{3 9}(\%)$ & Postoperative outcome $\dagger$ & No. \\
\hline Stroke & $16(41)$ & No/minimal symptoms & 7 \\
& & Persistent stroke & 6 \\
& & Deteriorating stroke & 2 \\
Transient ischemic attack & $11(29)$ & No symptoms & 8 \\
& & Stroke & 2 \\
Paraplegia & \multirow{2}{*}{$6(15)$} & No/minimal symptoms & 3 \\
& & Persistent paraplegia & 2 \\
Temporary paraparesis & $4(10)$ & No symptoms & 3 \\
& & Paraplegia & 1 \\
Encephalopathy (diffuse) & $2(5)$ & Progredient & 1 \\
\hline
\end{tabular}

*Data are presented as absolute numbers and percentages. $\dagger$ A total of 4 patients died postoperatively of hemodynamic reasons and neurologic outcome could not be assessed.

Preoperative limb malperfusion was present in 32 patients. Lower extremities were affected in most cases $(87 \%)$ and left-sided malperfusion was dominant in $55 \%$ of these cases. Standard surgical therapy for type A dissection resulted in restitution of blood flow to the affected extremities without additional interventions in all patients. In-hospital mortality tended to be higher in patients with limb malperfusion $(34.6 \%$ vs $19.1 \% ; P=.07)$, but 7 of 11 patients with limb malperfusion who died had more than one preoperative malperfusion syndrome. In-hospital mortality was $20 \%$ for patients with isolated limb malperfusion (ie, as a single malperfusion syndrome), which was not different from that of patients without limb malperfusion.

Visceral malperfusion occurred in only $8(3 \%)$ patients. Five $(62 \%)$ of these patients were in shock on admission and had elevated lactate levels. All 8 patients underwent immediate proximal aortic repair under deep hypothermia $\left(19.6^{\circ} \mathrm{C} \pm 2.3^{\circ} \mathrm{C}\right)$. Simultaneous exploratory laparotomy at the beginning of the surgical procedure was performed in the last 3 patients and ruled out necrotic gastrointestinal complications. High-dose inotropic/vasopressor support $\left(>10 \mu \mathrm{g} \cdot \mathrm{kg}^{-1} \cdot \mathrm{min}^{-1}\right)$ was required in all patients with visceral malperfusion after weaning from CPB. A total of 6 (75\%) patients died postoperatively, 5 within the first 24 hours after the operation. Autopsy examination was performed in 5 patients and demonstrated advanced visceral ischemia as a cause of death in all cases. One of the surviving patients required exploratory laparotomy and subsequent ileocecal resection on the third postoperative day. Both survivors are alive and doing well after 1 year of follow-up.

\section{DISCUSSION}

Despite several advances in surgical and anesthetic management of acute type A aortic dissection, this clinical entity remains one of the most lethal cardiovascular diseases. Several studies have demonstrated that preoperative status at presentation substantially influences perioperative outcomes. ${ }^{1-6,10}$ Fewer studies, however, have focused on the 
effects of preoperative status on long-term mortality. $3,7,10$ Caus and colleagues ${ }^{11}$ demonstrated the negative impact of preoperative complications on long-term outcome of elderly patients ( $>70$ years old) after surgery for acute type A aortic dissection. Although other studies have demonstrated the negative effects of preoperative malperfusion syndrome on survival, ${ }^{6,12}$ fewer have focused on the effects of various malperfusion syndrome subtypes. We therefore performed a retrospective analysis of a relatively large single-center experience with a particular focus on the effects of organ-specific malperfusion syndromes on perioperative and long-term mortality.

Our results confirm that aortic branch malperfusion is a significant risk factor for both perioperative and longterm mortality in patients with acute type A aortic dissection. Presence of malperfusion was associated with numerous postoperative complications (eg, respiratory dysfunction, renal failure, and stroke) in our study, resulting in a prolonged intensive care unit stay (11.4 \pm 9.7 days $)$ and increased perioperative mortality, similar to findings from other studies. ${ }^{1-11}$ Moreover, our results suggest that the presence of more than one malperfusion syndrome is associated with even worse in-hospital outcome than malperfusion of one end-organ ( $44 \%$ vs $25 \%$ in-hospital mortality).

The largest survival difference between groups with and without malperfusion could be observed during the immediate postoperative course and the first few months after hospital discharge (Figure 1). Survival curves ran parallel thereafter without obvious separation, an observation that has been reported by other authors. ${ }^{2}$ This observation would suggest that appropriate management of end-organ malperfusion can result in acceptable results, so long as patients can survive the early postoperative period.

The ideal therapeutic approach to patients with various types of preoperative malperfusion has not yet been established. Heinemann and colleagues ${ }^{13}$ published results of 33 surgically treated patients with different types of dissection-associated malperfusion syndromes. Most of these patients underwent surgical fenestration of the dissecting membrane with or without infrarenal grafting simultaneously with the proximal aortic repair, which resulted in an acceptable in-hospital mortality of $30 \%$. The need for prompt diagnosis and appropriate treatment of organ malperfusion in patients with acute aortic dissection has been stressed in this and other reports. ${ }^{13,14}$ Most authors advocate immediate repair of the proximal aorta as the treatment of choice, ${ }^{2,15,16}$ a strategy that we also followed during the study period. We found, similar to other authors, ${ }^{17,18}$ that persistent organ malperfusion after central aortic repair was unusual, occurring in only 1 patient in the current series. New malperfusion syndromes occurring after aortic repair were also unusual (observed in 3 patients) and were successfully treated with surgical or percutaneous interventions. Shiiya and coauthors ${ }^{19}$ proposed a mechanism-specific ap- proach in patients with vital organ malperfusion, which included central aortic surgery for aortic-type malperfusion and percutaneous interventions or coronary bypass grafting for branch-type malperfusion.

Some authors have suggested that patients with malperfusion syndromes, particularly those with visceral ischemia, should undergo delayed surgical intervention because of the increased risk of mortality associated with immediate surgery. Such a strategy involves percutaneous interventional revascularization of ischemic end-organs and a period of waiting for the resolution of reperfusion injury, followed by planned surgery of the proximal aorta. ${ }^{7,8,20,21}$ Although delayed surgery may be an attractive alternative in certain subgroups, it is important to keep in mind that mortality rates for conservatively treated type A aortic dissection are substantial and are directly related to time from diagnosis. ${ }^{22}$

Coronary malperfusion was associated with very high inhospital mortality $(39 \%)$ and dismal long-term survival ( $22 \%$ at 5-year follow-up) in the current study. Similar results have been published by other authors. ${ }^{23-25}$ Nearly half of our patients with coronary malperfusion were hemodynamically unstable preoperatively, and surgery was started under cardiopulmonary resuscitation conditions in $20 \%$ of such cases. All 8 patients with postoperative support with extracorporeal membrane oxygenation died of persisting refractory low cardiac output syndrome after a complex postoperative course. We believe that immediate surgical repair restoring coronary perfusion is the only viable option in these critically ill patients, but that their prognosis is guarded. In addition, inability to wean from CPB is associated with a dismal prognosis and postoperative mechanical support is probably futile.

Another surgical dilemma is the treatment of patients with preoperative cerebral malperfusion. Estrera and coauthors ${ }^{16}$ reported on favorable postoperative results in patients with type A dissection and preoperative stroke, with the best results found in patients who underwent surgical repair within 10 hours after the onset of cerebral symptoms. Our results are comparable: $25 \%$ hospital mortality and $48 \%$ complete resolution of cerebral symptoms after immediate surgical repair. Seven $(44 \%)$ patients with preoperative stroke underwent surgery within 10 hours after the onset of cerebral symptoms in our series (vs 70\% in the Estrera series), and 5 of these patients displayed improved neurologic status postoperatively. However, we also observed postoperative deterioration and eventual cerebral death in 2 such patients. We therefore agree that time to surgery may play an important role for neurologic recovery in patients with preoperative stroke, but we would state that an improvement in neurologic outcome cannot be guaranteed. Furthermore, those patients who exhibited an improved neurologic status postoperatively tended to be younger $(58.4 \pm 11.6$ vs $65.0 \pm 16.3$ years; $P=.4)$ and presented less frequently with preoperative shock $(14 \%$ vs $38 \% ; P=.1)$. We also found that patients with preoperative TIA 
occasionally exhibited worsening of neurologic status after surgery, although the absolute numbers were small ( 3 of 11 having postoperative stroke).

Two patients in the current series were in a preoperative coma and both died postoperatively. These patients are known to be at extremely high surgical risk and are therefore probably best treated with a "wait and see" delayed surgical approach after the neurologic status has improved. Such a recommendation has also been made by other authors. ${ }^{7,16,26}$

There is little information in the literature from which to provide recommendations for management of acute type A dissection complicated by preoperative paraplegia. Experience is limited to analysis of individual cases in previously reported series. ${ }^{2,17,27}$ We proceeded with immediate surgery in all patients with preoperative spinal malperfusion and observed complete recovery of spinal cord function in $60 \%$ of cases.

On the basis of our findings and those of other investigators, we therefore advocate immediate surgical repair in patients with acute type A aortic dissection and central nervous system malperfusion, although a "wait and see" approach is reasonable in patients who are in a coma.

Proximal aortic repair resulted in reperfusion of all ischemic extremities in patients with limb malperfusion in the current study. No additional procedures for persisting limb ischemia were required postoperatively. Increased in-hospital mortality of $35 \%$ in this patient subgroup was probably due to the increased incidence of combined malperfusion syndromes, being present in nearly half of these patients. In-hospital mortality in patients with isolated limb malperfusion, however, was a more respectable $20 \%$. Other authors have recently observed a high rate of acute renal failure in type A patients with preoperative limb malperfusion. ${ }^{28}$ Our study revealed that $46 \%$ of patients with limb malperfusion required hemodialysis postoperatively versus $20 \%$ of patients without it $(P=.01)$. Possible explanations for this finding are simultaneous renal vascular impairment by the aortic dissection and/or severe reperfusion injury of a large tissue area with subsequent release of nephrotoxic metabolites.

Visceral malperfusion is a rare but threatening presentation of acute type A aortic dissection. ${ }^{29}$ It is associated with poor in-hospital outcome, even after successful proximal aortic surgery. ${ }^{8,17,18}$ Our study confirmed these findings with a hospital mortality rate of $75 \%$. Most of these patients died of visceral ischemia during the first 24 hours after surgery, despite the fact that sufficient mesenteric reperfusion was achieved. In this context, we agree with authors advocating percutaneous interventional reperfusion and a delayed surgical strategy, provided that no cardiac tamponade or coronary malperfusion exists. Some experienced centers have demonstrated a reduction in mortality rate to approximately $40 \%$ with percutaneous intervention and delayed surgery. ${ }^{7,27}$ Furthermore, we found it useful to perform an ex- ploratory laparotomy before proceeding with the proximal aortic surgery in patients with suspected mesenteric ischemia to rule out necrotic gastrointestinal complications.

In the current study, we did not attempt to analyze the effects of preoperative renal malperfusion because of difficulties establishing this diagnosis. That is, a variety of causes can lead to preoperative renal insufficiency with or without compromise of the renal arteries. Although type A dissection frequently involves the left renal artery, sufficient residual perfusion of the right kidney is usually present to avoid complete anuria. Some other authors have identified preoperative renal malperfusion as an independent risk factor of in-hospital mortality. ${ }^{6,12}$

\section{CONCLUSIONS}

We have examined the effects of preoperative malperfusion, with a particular focus on various end-organ subtypes, on perioperative and long-term outcomes after surgery for type A dissection. Coronary malperfusion is associated with an increased risk of postoperative mortality, but immediate surgical repair is still recommended provided that postoperative mechanical support is not implemented. We also advocate immediate proximal aortic repair in patients with other malperfusion syndromes, with the exception of those with coma or advanced visceral malperfusion. Such patients should be managed with percutaneous interventional procedures and delayed surgery because of the dismal prognosis associated with immediate surgical therapy.

\section{References}

1. Rampoldi V, Trimarchi S, Eagle KA, Nienaber CA, Oh JK, Bossone E, et al. Simple risk models to predict surgical mortality in acute type A aortic dissection: the International Registry of Acute Aortic Dissection score. Ann Thorac Surg. 2007; 83:55-61.

2. Geirsson A, Szeto WY, Pochettino A, McGarvey ML, Keane MG, Woo YJ, et al. Significance of malperfusion syndromes prior to contemporary surgical repair for acute type A dissection: outcomes and need for additional revascularizations. Eur J Cardiothorac Surg. 2007;32:255-62.

3. Chiappini B, Schepens M, Tan E, Dell'Amore A, Morshuis W, Dossche K, et al. Early and late outcomes of acute type A aortic dissection: analysis of risk factors in 487 consecutive patients. Eur Heart J. 2005;26:180-6.

4. Trimarchi S, Nienaber CA, Rampoldi V, Myrmel T, Suzuki T, Mehta RH, et al. Contemporary results of surgery in acute type A aortic dissection: the International Registry of Acute Aortic Dissection experience. J Thorac Cardiovasc Surg. 2005;129:112-22.

5. Bachet J. Acute type A aortic dissection: can we dramatically reduce the surgical mortality? Ann Thorac Surg. 2002;73:701-3.

6. Kazui T, Washiyama N, Bashar AH, Terada H, Suzuki T, Ohkura K, et al. Surgical outcome of acute type A aortic dissection: analysis of risk factors. Ann Thorac Surg. 2002;74:75-82.

7. Patel HJ, Williams DM, Dasika NL, Suzuki Y, Deeb GM. Operative delay for peripheral malperfusion syndrome in acute type A aortic dissection: a long-term analysis. J Thorac Cardiovasc Surg. 2008;135:1288-96.

8. Yagdi T, Atay Y, Engin C, Mahmudov R, Tetik O, Iyem H, et al. Impact of organ malperfusion on mortality and morbidity in acute type A aortic dissections. JCard Surg. 2006;21:363-9.

9. Crawford ES, Kirklin JW, Naftel DC. Surgery for acute dissection of ascending aorta: should the arch be included? J Thorac Cardiovasc Surg. 1992;104:46-59.

10. Immer FF, Grobety V, Lauten A, Carrel TP. Does malperfusion syndrome affect early and mid-term outcome in patients suffering from acute type A aortic dissection? Interact Cardiovasc Thorac Surg. 2006;5:187-90. 
11. Caus T, Frapier JM, Giorgi R, Aymard T, Riberi A, Albat B, et al. Clinical outcome after repair of acute type A dissection in patients over 70 years-old. Eur J Cardiothorac Surg. 2002;22:211-7.

12. Apaydin AZ, Buket S, Posacioglu H, Islamoglu F, Calkavur T, Yagdi T, et al. Perioperative risk factors for mortality in patients with acute type A aortic dissection. Ann Thorac Surg. 2002;74:2034-9.

13. Heinemann MK, Buehner B, Schaefers HJ, Jurmann MJ, Laas J, Borst HG. Malperfusion of the thoracoabdominal vasculature in aortic dissection. J Card Surg. 1994;9:748-55.

14. Okita Y, Takamoto S, Ando M, Morota T, Kawashima Y. Surgical strategies in managing organ malperfusion as a complication of aortic dissection. Eur J Cardiothorac Surg. 1995;9:242-7.

15. Fann JI, Sarris GE, Mitchell RS, Shumway NE, Stinson EB, Oyer PE, et al. Treatment of patients with aortic dissection and presenting with peripheral vascular compromise. Ann Surg. 1990;212:705-13.

16. Estrera AL, Garami Z, Miller CC, Porat EE, Achouh PE, Dhareshwar J, et al. Acute type A aortic dissection complicated by stroke: can immediate repair be performed safely? J Thorac Cardiovasc Surg. 2006;132:1404-8.

17. Girardi LN, Krieger KH, Lee LY, Mack CA, Tortolani AJ, Isom OW. Management strategies for type A dissection complicated by peripheral vascular malperfusion. Ann Thorac Surg. 2004;77:1309-14.

18. Slonim SM, Nyman U, Semba CP, Miller DC, Mitchell RS, Dake MD. Aortic dissection: percutaneous management of ischemic complications with endovascular stents and balloon fenestration. J Vasc Surg. 1996;23:241-53.

19. Shiiya N, Matsuzaki K, Kunihara T, Murashita T, Matsui Y. Management of vital organ malperfusion in acute aortic dissection: proposal of a mechanism-specific approach. Gen Thorac Cardiovasc Surg. 2007;55:85-90.

20. Tsagakis K, Pizanis N, Kamler M, Konorza T, Zoepf T, Erbel R, et al. ICU controlled delay for acute type A aortic dissection repair after intervention for total visceral malperfusion: a way out of a dilemma? Thorac Cardiovasc Surg. 2008 56:298-305.

21. Fabre O, Vincentelli A, Willoteaux S, Beregi JP, Prat A. Preoperative fenestration for type A acute aortic dissection with mesenteric malperfusion. Ann Thorac Surg. 2002;73:950-1.

22. Hagan PG, Nienaber CA, Isselbacher EM, Bruckman D, Karavite DJ, Russman PL, et al. The International Registry of Acute Aortic Dissection (IRAD). New insights into an old disease. JAMA. 2000;283:897-903.

23. Kawahito K, Adachi H, Murata S, Yamaguchi A, Ino T. Coronary malperfusion due to type A aortic dissection: mechanism and surgical treatment. Ann Thorac Surg. 2003;76:1471-6.

24. Eren E, Toker ME, Tuncer A, Keles C, Erdogan HB, Anasiz H, et al. Surgical management of coronary malperfusion due to type A aortic dissection. $J$ Card Surg. 2007;22:2-6

25. Neri E, Toscano T, Papalia U, Frati G, Massetti M, Capannini G, et al. Proxima aortic dissection with coronary malperfusion: presentation, management, and outcome. J Thorac Cardiovasc Surg. 2001;121:552-60.

26. Tanaka H, Okada K, Yamashita T, Morimoto Y, Kawanishi Y, Okita Y. Surgical results of acute aortic dissection complicated by cerebral malperfusion. Ann Thorac Surg. 2005;80:72-6.

27. Lauterbach SR, Cambria RP, Brewster DC, Gertler JP, LaMuraglia GM Isselbacher EM, et al. Contemporary management of aortic branch compromise resulting from acute aortic dissection. J Vasc Surg. 2001;33:1185-92.

28. Long SM, Nair D, Halandras PM, Kasirajan K, Milner R, Chen EP. Ileofemora malperfusion complicating type A dissection: revascularization prevents renal failure. Ann Thorac Surg. 2007;84:2099-101.

29. Upchurch GR, Nienaber C, Fattori R, Evangelista A, Oh J, Cooper JV, et al. Acute aortic dissection presenting with primarily abdominal pain: a rare manifestation of a deadly disease. Ann Vasc Surg. 2005;19:367-73. 